ఠ

\title{
Patient preferences for inhaler devices in chronic obstructive pulmonary disease: experience with Respimat ${ }^{\circledR}$ Soft Mist ${ }^{\text {TM }}$ Inhaler
}

This article was published in the following Dove Press journal:

International Journal of COPD

29 October 2009

Number of times this article has been viewed

\author{
Richard Hodder' \\ David Price ${ }^{2}$ \\ 'Divisions of Pulmonary and Critical \\ Care, University of Ottawa, Ottawa, \\ Ontario, Canada; ${ }^{2}$ Department of \\ General Practice and Primary Care, \\ University of Aberdeen, Aberdeen, \\ Scotland
}

\begin{abstract}
Current guidelines for the management of chronic obstructive pulmonary disease (COPD) recommend the regular use of inhaled bronchodilator therapy in order to relieve symptoms and prevent exacerbations. A variety of inhaler devices are currently available to COPD patients, and the choice of device is an important consideration because it can influence patients' adherence to treatment, and thus potentially affect the long-term outcome. The Respimat ${ }^{\circledR}$ Soft Mist $^{\mathrm{TM}}$ Inhaler (SMI) generates a slow-moving aerosol with a high fine particle fraction, resulting in deposition of a higher proportion of the dose in the lungs than pressurized metered-dose inhalers (pMDIs) or some dry powder inhalers (DPIs). We review clinical studies of inhaler satisfaction and preference comparing Respimat ${ }^{\circledR}$ SMI against other inhalers in COPD patients. Using objective and validated patient satisfaction instruments, Respimat ${ }^{\mathbb{B}}$ SMI was consistently shown to be well accepted by COPD patients, largely due to its inhalation and handling characteristics. In comparative studies with pMDIs, the patient total satisfaction score with Respimat ${ }^{\circledR}$ SMI was statistically and clinically significantly higher than with the pMDI. In comparative studies with DPIs, the total satisfaction score was statistically significantly higher than for the Turbuhaler ${ }^{\circledR}$ DPI, but only the performance domain of satisfaction was clinically significantly higher for Respimat $^{\circledR}$ SMI. Whether the observed higher levels of patient satisfaction reported with Respimat ${ }^{\circledR}$ SMI might be expected to result in improved adherence to therapy and thus provide benefits consistent with those recently shown to be associated with sustained bronchodilator treatment in patients with COPD remains to be proven.
\end{abstract}

Keywords: Respimat ${ }^{\circledR}$ Soft Mist ${ }^{\mathrm{TM}}$ Inhaler, pressurized metered-dose inhalers, pressurized metered-dose inhalers, inhaler devices

\section{Introduction: inhalation therapy in COPD}

Chronic obstructive pulmonary disease (COPD) poses many therapeutic challenges, both for patients and their physicians. Unlike asthma, COPD is not fully reversible and causes a progressive deterioration in lung function over time. Furthermore, the underlying inflammatory process in COPD differs from that in asthma and is less susceptible to treatment with inhaled corticosteroids. ${ }^{1,2}$ Hence, current pharmacological management of COPD, as recommended in treatment guidelines such as those of the Global Initiative for Chronic Obstructive Lung Disease (GOLD) ${ }^{3}$ focuses primarily on achieving sustained bronchodilation in order to relieve symptoms by decreasing both airway obstruction and pulmonary hyperinflation. These recommendations are based on a substantial body of evidence showing that regular treatment with long-acting bronchodilators relieves symptoms and reduces exacerbations in symptomatic patients with COPD. ${ }^{3,4}$ In addition, recent data from large clinical trials in COPD
Correspondence: Richard Hodder Professor of Medicine, Divisions of Pulmonary and Critical Care, University of Ottawa, The Ottawa Hospital, 1053 Carling Ave,

Ottawa, ON, Canada KIY 4E9 Email rhodder@ottawahospital.on.ca 
suggest that sustained bronchodilation with both long-acting anticholinergic and beta ${ }_{2}$-adrenergic bronchodilators is associated with a reduced loss of lung function over time, ${ }^{5-8}$ an improvement in quality of life $^{5-8}$ and possibly reduced mortality. ${ }^{6,7}$

A variety of inhaler devices are available for bronchodilator treatment in COPD patients, including pressurized metereddose inhalers (pMDIs), dry powder inhalers (DPIs), and nebulizers. ${ }^{9}$ Each of these devices has its own advantages and disadvantages: pMDIs are convenient and relatively inexpensive, but many patients find it difficult to use them correctly, often because of problems in coordinating actuation or inhaling too quickly. ${ }^{9,10}$ Furthermore, poor inhaler technique has been shown in asthma patients to result in suboptimal treatment and outcomes. ${ }^{11,12}$ DPIs are breath-actuated, so coordination of actuation and inhalation is not necessary, but many patients are unable to use these devices correctly ${ }^{9,13}$ and delivery to the lungs may be decreased if, for example, inhalation is too slow or if the time to peak inspiratory flow is too long. ${ }^{9}$ Nebulizers are generally bulky and inconvenient, can be expensive, and require regular maintenance and long treatment times, and hence tend to be used mainly by less mobile patients. ${ }^{9}$ Given the relative advantages and disadvantages of each device type, the choice of inhaler for COPD treatment in an individual patient will require careful consideration of the patient's specific needs and preferences as well as the patient's inhaler technique. ${ }^{11,14}$

A number of factors may influence COPD patients' attitudes to inhaled therapy and their preferences for a specific device (Table 1). ${ }^{15-17}$ These include disease-related issues such as the perceived efficacy of treatment in the face of a progressive decline in lung function, an aversion to or concerns about regular medication use, concern about drug side effects, and device-related issues such as the convenience, ease of use of the device, cost, perceived device efficacy and physician device preference. It is not possible to predict which factors will have the greatest influence on adherence to inhaled therapy, as this will vary from patient to patient. However in practice, perceived efficacy of therapy is likely to have a strong influence on inhaler adherence.

The choice of inhaler for a particular patient is an important issue in COPD because of the importance of adherence to therapy, which is likely to be influenced by patients' attitudes to the device and their experiences in using it. If the patient feels a therapy is not working, adherence is likely to be low, but poor efficacy could also be caused by the inhaler technique being incorrect for the device being used. This may potentially affect the outcome of treatment, ${ }^{18,19}$
Table I Factors affecting patients' attitudes to COPD therapy and their preferences for a specific inhaler device ${ }^{12-17}$

\begin{tabular}{l} 
Disease and drug factors \\
Progressive nature of COPD (declining benefit) \\
Concerns about regular medication, including side effects \\
Potential side-effects of treatment \\
Perceived drug efficacy (symptom relief/prevention of exacerbations) \\
Device factors \\
Perceived device efficacy \\
Ease of use of device \\
- Need for actuation/inhalation coordination \\
- Ability to actuate device (strength, arthritis issues) \\
Convenience of device \\
- Dose and refill frequency \\
- Dose counter \\
Feelings of stigmatization due to need for device use in public \\
Physician device preference \\
Availability of drug/device preparations \\
"Brand loyalty" \\
Cost \\
Time to learn; clear instructions \\
Size, weight, taste, device appearance \\
Cleaning issues \\
Disposability/environmental issues \\
\hline
\end{tabular}

as reflected in the observation by a former USA Surgeon General that "Drugs don't work if patients don't take them". ${ }^{20}$ The issue is controversial however, as two large systematic reviews of the clinical inhaler literature have concluded that there is no strong evidence that the type of inhaler device used has any affect on clinical outcome in patients with asthma and COPD. ${ }^{21,22}$ However, there are important caveats that must be considered before accepting these analyzes at face value. The vast majority of the clinical studies reviewed in these analyzes compared inhalers in licensing studies, which are usually designed and powered to show equivalence and have often tested doses of drugs that are at the top of their respective dose-response curves, where response is insensitive to changes in dose. Furthermore, these studies use highly selected patients with excellent inhaler technique who not only consent to participate, but also receive special care consisting of regular, reinforcing contact with healthcare professionals, a feature that emphasizes adherence to therapy. The indications from real-life studies in asthma are that inhalers do make a difference to disease control outcomes, ${ }^{23,24}$ 
but studies of similar design have not yet been done in COPD patients. The American College of Chest Physicians and the American College of Asthma, Allergy and Immunology (ACCP/ACAAI) have also recently concluded that all of the marketed inhalation devices can work equally well, provided that patients can and will use the devices as prescribed. ${ }^{22}$ The guidelines committee acknowledged the limitations of this type of analysis, which for the most part was dependent on industry-sponsored comparative studies which were designed to show device equivalence in highly selected and trained groups of patients, under non-real life conditions. Importantly, most such trials have not attempted to use validated device satisfaction or preference assessment tools.

Notwithstanding these uncertainties, it is clear that in surveys of healthcare professionals, ease of use and patient preference for device are regarded as the most important considerations when selecting an inhaler for patients. ${ }^{25,26}$ Furthermore, it is also clear that not all patients can use all inhalers equally well. Patients clearly vary in their preferences for different inhalers ${ }^{27,28}$ and frequently do not see devices as being interchangeable.

Although relatively few studies have specifically examined adherence to therapy in COPD patients, the available evidence suggests that (as in other chronic diseases) adherence is poor. ${ }^{19,29}$ For example, in the Lung Health Study, almost $70 \%$ of participants reported "satisfactory" or better compliance at 4 months, but only $48 \%$ were classified as showing this level of adherence at 1 year. ${ }^{30}$ Similarly, a cohort study in the USA found that approximately $60 \%$ of elderly patients (aged 65 years and older) with moderate or severe COPD were poorly adherent to inhaled corticosteroid therapy. ${ }^{31}$ There is good evidence that in asthma patients, poor adherence to therapy is associated with worse outcomes, ${ }^{32-34}$ and the limited evidence available suggests that this is also true in COPD. For example, in the US cohort study described above, better adherence was associated with a $20 \%$ decrease in the number of hospital visits over one year. ${ }^{31}$ Similarly, in a study involving 82 COPD patients who were receiving home nebulizer therapy, 46 patients (56\%) were found to be poorly adherent and this trait was associated with impaired quality of life..$^{35}$ Thus, it does appear that in real life conditions, choice of inhaler device can have an impact on disease control, and that the patient-device interface is crucial. Therefore, there is clearly scope for improving adherence to inhalation therapy in COPD.

Soft mist inhalers (SMIs) represent a new development in inhaled bronchodilator therapy in COPD. ${ }^{9}$ These are propellant-free, multiple-dose devices that use liquid formulations similar to those in nebulizers. Currently, the only
SMI in clinical use for the treatment of COPD is the Respimat $^{\circledR}$ Soft Mist ${ }^{\mathrm{TM}}$ Inhaler (Respimat ${ }^{\circledR}$ SMI; Boehringer Ingelheim, Ingelheim, Germany). The Respimat ${ }^{\circledR}$ SMI uses the energy of a compressed spring to generate an aerosol over a period of about one second with a high fine particle fraction and with a velocity approximately one-tenth of that generated by chlorofluorocarbon-based pMDIs (CFC-pMDIs). ${ }^{36}$ Scintigraphic studies have shown that as a result of these device and aerosol characteristics, oropharyngeal deposition is reduced and lung deposition with Respimat ${ }^{\mathbb{R}} \mathrm{SMI}$ is several times greater than with CFC-pMDIs and the Turbuhaler ${ }^{\mathbb{B}}$ DPI. ${ }^{37,38}$ Because of this, smaller nominal doses of drug can be used in COPD patients, ${ }^{39}$ and Respimat ${ }^{\circledR}$ SMI can increase lung deposition even in COPD patients with poor inhaler technique. ${ }^{40}$

This paper reviews the available data on patient preferences from clinical studies with the Respimat ${ }^{\circledR}$ SMI in COPD patients, including a discussion of the instruments available for measuring patient satisfaction with inhalers. Data from both comparative and non-comparative studies with Respimat ${ }^{\mathbb{B}}$ SMI are reviewed. In three comparative studies, patients used Respimat ${ }^{\mathbb{R}}$ SMI and the comparator device, but because masking of the devices being compared was not feasible, patients and investigators knew the identity of the two test devices. Two of these trials used double-dummy trial designs.

\section{Measurement of patient satisfaction and preference with inhaler devices}

Patient satisfaction and preference with inhaler devices have attracted increasing attention in recent years, because of the potential impact that patients' experiences with their inhalers might have on adherence to therapy and hence long-term outcome. ${ }^{16,18,41}$ Inhaler preference is now recognized as a valid patient-reported outcome, and although the science of studying satisfaction or preference with medication or a device is relatively new, the basic principles are clear. ${ }^{42}$ Until recently, however, these measurement principles have not penetrated widely into the design of inhaler satisfaction and preference trials, and standards for measuring and reporting patient satisfaction and preferences have varied widely between studies. ${ }^{16,17}$ The types of instruments commonly used in inhaler satisfaction and preference studies to date have ranged from a simple preference question to non-validated proprietary questionnaires. Response scales used have varied from open-ended questions, through poorly-defined response scales, to visual analogue and Likert scales. Furthermore, most questionnaires have been developed without input from patients or experts in psychometric testing. This lack of 
precision with measurement has made the device preference literature difficult to interpret.

In designing a rigorous inhaler satisfaction/preference trial, the single most important factor is the use of a reliable and valid inhaler satisfaction/preference measurement tool ${ }^{16,17}$ and such instruments have only recently become available. ${ }^{43,44}$ In a recent review of 30 published inhaler preference studies, only 2 studies were found to have used robust instruments for measuring preference and satisfaction. ${ }^{16}$ The 2 instruments in question, the Patient Device Experience Assessment $(P D E A)^{43}$ and the Patient Satisfaction and Preference Questionnaire (PASAPQ), ${ }^{44}$ were developed by experts in psychometric testing and subjected to field testing. Of these, only the PASAPQ has a published validation. ${ }^{44}$ The PASAPQ (Table 2) is a self-administered 15-item instrument that includes 13 satisfaction items, a preference item, and a question on willingness to continue using the device. Details on the development and use of the PASAPQ have been published ${ }^{44,45}$ and included obtaining input from patients and clinical experts, using quantitative and qualitative analyses to select among the items, and psychometric testing in clinical studies applying techniques commonly used in the development of patient reported outcome measures. It was developed without regard for a particular device or treatment in order to be widely applicable to respiratory treatments. In part 1 of the PASAPQ, patients rate each of the 13 satisfaction items using a 7-point Likert scale ( 1 = very dissatisfied and 7 = very satisfied), as well as answer a global satisfaction question. In part 2, patients answer global questions on inhaler preference and on willingness to continue using the device. The PASAPQ has been shown to be reliable and responsive in discriminating between preferred and non-preferred devices in patients with COPD and asthma. ${ }^{44}$ Validation of the PASAPQ included a determination of the minimum important difference (MID) between devices, allowing an assessment of the clinical significance of differences observed in testing. The MID was estimated using both anchor-based and distributional approaches, and although a difference of 3 or 4 points was found to be sufficient to achieve a small effect, most MID estimates were in the 8- to 10-point range. For this reason, a 10-point difference between devices for the Performance, Convenience and Total Satisfaction scores has been recommended as a conservative indication of a difference that is meaningful to patients. ${ }^{44,45}$

\section{Respimat $^{\circledR}$ SMI: ease-of-use studies}

Ease-of-use studies for the Respimat ${ }^{\circledR}$ SMI have been conducted in patients naïve to the device and have mainly employed simple, non-validated, questionnaires which were nevertheless specific to the Respimat ${ }^{\circledR}$ SMI. Results from

Table 2 Items and scoring for the patient satisfaction and preference questionnaire (PASAPQ) ${ }^{44,45}$

\begin{tabular}{|c|c|c|c|c|}
\hline \multicolumn{2}{|c|}{ Domain } & Question & Description & Scoring \\
\hline \multirow{13}{*}{$\begin{array}{l}0 \\
\frac{0}{0} \\
\frac{n}{\circledR} \\
0\end{array}$} & \multirow{7}{*}{ 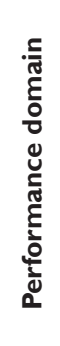 } & QI & Overall feeling of inhaling & \multirow{14}{*}{$\begin{array}{l}\text { All items scored on a 7-point Likert scale: } \\
\text { I = Very dissatisfied } \\
2 \text { = Dissatisfied } \\
3 \text { = Somewhat dissatisfied } \\
4=\text { Neither satisfied nor dissatisfied } \\
5=\text { Somewhat satisfied } \\
6 \text { = Satisfied } \\
7 \text { = Very satisfied }\end{array}$} \\
\hline & & Q2 & Inhaled dose goes to lungs & \\
\hline & & Q3 & Amount of medication left & \\
\hline & & Q4 & Works reliably & \\
\hline & & Q5 & Ease of inhaling a dose & \\
\hline & & Q10 & Using the inhaler & \\
\hline & & QII & Speed medicine comes out & \\
\hline & \multirow{6}{*}{ 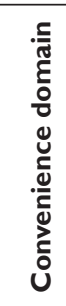 } & Q6 & Instructions for use & \\
\hline & & Q7 & Size of inhaler & \\
\hline & & Q8 & Durability of inhaler & \\
\hline & & Q9 & Ease of cleaning inhaler & \\
\hline & & $\mathrm{Q} 12$ & Ease of holding during use & \\
\hline & & Q13 & Convenience of carrying & \\
\hline \multirow{3}{*}{\multicolumn{2}{|c|}{$\begin{array}{l}\text { Stand alone } \\
\text { questions }\end{array}$}} & Q14 & Overall satisfaction & \\
\hline & & \multicolumn{2}{|c|}{ Preference } & $\begin{array}{l}\text { o Prefer inhaler I } \\
\text { o Prefer Inhaler } 2 \\
\circ \text { No preference }\end{array}$ \\
\hline & & \multicolumn{2}{|c|}{ Willingness to continue } & $\begin{array}{l}\text { Each inhaler given a score between } \\
0 \text { and } 100\end{array}$ \\
\hline
\end{tabular}


several non-comparative studies with the Respimat ${ }^{\circledR}$ SMI delivering placebo, ipratropium or ipratropium/fenoterol are shown in Table 3 . The majority of participants in these studies found the device easy to use regardless of patient age and felt confident in using the device after 1 day of use.

Ease of use was also assessed during a trial comparing Respimat $^{\circledR}$ SMI and a hydrofluoroalkane (HFA) pMDI (Boehringer Ingelheim study number 215.1357). ${ }^{27}$ The majority of patients (96\% to $98 \%$ ) were able to achieve satisfactory technique within five attempts with each device and slightly more patients were judged to have retained good technique after 7 weeks with Respimat ${ }^{\circledR}$ SMI than with the HFA-pMDI (96.9\% and 93.8\%, respectively).

\section{Respimat $^{\circledR}$ SMI: satisfaction and preference studies}

Satisfaction and preference assessments have been incorporated into various trials of Respimat ${ }^{\circledR}$ SMI and these are summarized in Tables 3 and 4. In most of the trials, the device was used to deliver bronchodilators, usually ipratropium bromide plus fenoterol. In two of the three comparative trials, the inhalers being compared contained the same active drug substance. Patient satisfaction with Respimat ${ }^{\circledR}$ SMI was also assessed using post hoc questionnaires at the end of treatment in subsets of COPD patients ( $\mathrm{n}=47$ and 129 , respectively) in the two clinical trials from Germany (Boehringer Ingelheim 244.2484) and Canada (Boehringer Ingelheim 215.1349). In the German trial, patients aged 37 to 87 years received either ipratropium bromide plus fenoterol $\left(\right.$ Berodual $^{\circledR}$ ) or placebo once daily for 12 weeks; in the Canadian trial, patients aged 19 to 88 years received ipratropium bromide or placebo once daily for 6 months. All patients in the German study and $92 \%$ of those in the Canadian study had previously used a pMDI. In both studies, patients were asked to rate their satisfaction with Respimat ${ }^{\circledR}$ SMI on a scale of 1 to 10 , where 1 indicated "extremely dissatisfied" and 10 indicated "extremely satisfied." Ratings of 9 or 10 were given by $74 \%$ of patients in the Canadian study and $64 \%$ of those in the German study. The most commonly reported reasons for satisfaction with Respimat ${ }^{\circledR}$ SMI were inhalation characteristics (eg, the feeling of a better effect than with a pMDI), or features relating to handling of the device (eg, ease and convenience of use), and a high proportion of patients $(80 \%$ and $72 \%$ in the Canadian and German studies, respectively) said they were "extremely interested" in continuing with Respimat ${ }^{\circledR}$ SMI rather than their current inhalers.

In an observational cohort study in Germany (Boehringer Ingelheim 215.1362), 4602 patients with asthma, COPD

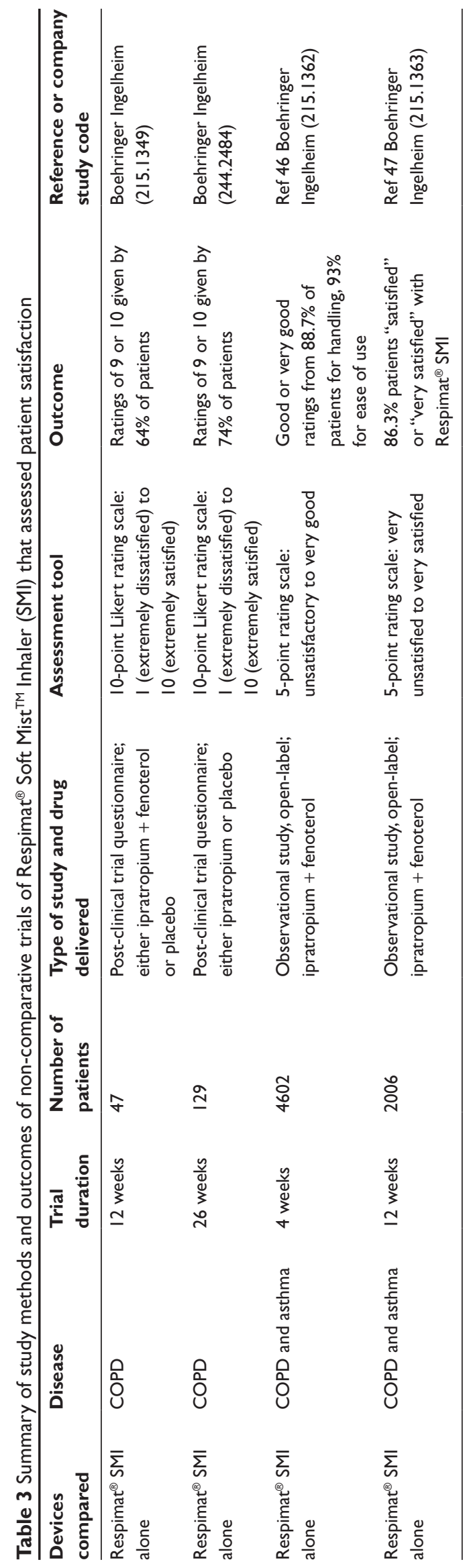


or both, were interviewed 4 weeks after starting a new prescription of ipratropium bromide plus fenoterol via Respimat ${ }^{\circledR}$ SMI. ${ }^{46}$ On a 5-point scale from "unsatisfactory" to "very good", ratings of "good" or "very good" were given by $88.7 \%$ of patients for handling of Respimat ${ }^{\circledR}$ SMI and $93 \%$ for how easy it was to inhale from the device. Therapy with Respimat ${ }^{\circledR}$ SMI was rated better or much better than therapy with the patient's previous inhaler by $81 \%$ of patients, and $94.4 \%$ actually continued using Respimat ${ }^{\circledR}$ SMI. ${ }^{46}$ In a further study (Boehringer Ingelheim study number 215.1363), 2006 patients with asthma, COPD, or both received ipratropium bromide plus fenoterol via Respimat ${ }^{\circledR}$ SMI for 12 weeks, and patient and physician satisfaction with the device were assessed by questionnaire after 4,8 , and 12 weeks' treatment. ${ }^{47}$ At 4 weeks, $1431(71.3 \%)$ patients reported that they were "satisfied" or "very satisfied" with Respimat ${ }^{\circledR}$ SMI and this number grew to $1731(86.3 \%)$ after 12 weeks of treatment. At the end of the study, the majority of physicians and patients preferred Respimat ${ }^{\circledR}$ SMI to their previous therapy. ${ }^{47}$

In 3 trials that have compared Respimat ${ }^{\circledR}$ SMI with other devices, patients' comparative satisfaction and preference for the devices were assessed with the validated PASAPQ instrument and the results of these trials are discussed below. ${ }^{27,48,49}$

\section{Comparison with pMDls}

Patient preferences for Respimat ${ }^{\circledR}$ SMI and a HFA pMDI were compared as the primary endpoint in a non-blinded randomized crossover trial in patients with asthma, COPD, or both (Boehringer Ingelheim study number 215.1357). ${ }^{27}$ Patients received equivalent doses of ipratropium bromide plus fenoterol via each device for 7 weeks, and satisfaction and preference were assessed using the PASAPQ at the end of each treatment period. Of 224 patients analyzed, $72.3 \%$ preferred Respimat ${ }^{\circledR}$ SMI and $17.4 \%$ preferred the HFA pMDI $(P<0.001)$ (Figure 1a). This preference was unaffected by age or the presence of disorders that might have adversely affected inhaler handling. Mean satisfaction scores in the convenience domain were very similar for the 2 devices, but Respimat ${ }^{\circledR}$ SMI scored significantly better than the HFA pMDI in the performance domain, resulting in significantly higher total PASAPQ scores (Table 4). ${ }^{27}$ Mean total satisfaction score differences of 10.8 points on the PASAPQ indicated that the Respimat ${ }^{\circledR}$ SMI met the pre-determined MID for a clinically meaningful difference between devices ${ }^{44}$ At the end of the study, the median scores for willingness to continue using the device were 85 for Respimat ${ }^{\circledR}$ SMI and 50 for the HFA pMDI, on a scale of 0 to 100 where $0=$ "not willing" 
A) vs pMDI

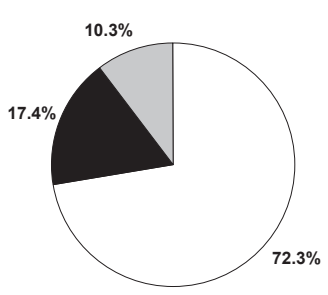

Preferred Respimat ${ }^{\circledR}$ SMI

Preferred other inhaler

No preference for either device, or no reply

B) vs Turbuhaler ${ }^{\circledR}$

C) vs Diskus ${ }^{\circledR}$
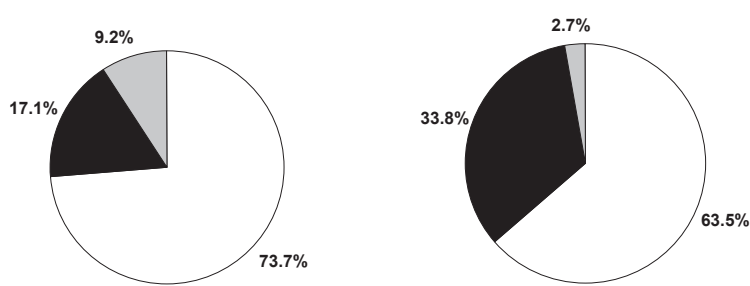

Figure I Proportion of patients indicating preference for Respimat ${ }^{\circledR}$ Soft Mist ${ }^{\mathrm{TM}}$ Inhaler (SMI) or an alternative inhaler device in 3 studies that used the Patient Satisfaction and Preference Questionnaire (PASAPQ): A) Pressurized metered-dose inhaler (pMDI) in a clinical study $\left.(\mathrm{n}=224) ;{ }^{27} \mathbf{B}\right)$ Turbuhaler $^{\circledR}$ in a clinical study $\left.(\mathrm{n}=153) ;{ }^{48} \mathbf{C}\right)$ Diskus ${ }^{\circledR}$ in an observational study $(\mathrm{n}=150){ }^{49}$

and $100=$ "definitely willing" $(P<0.001$ for median difference). Clinical efficacy in this trial was assessed using daily diary cards which recorded evening peak expiratory flow rates, rescue medication use and daytime and nighttime symptom scores. The fact that no significant differences in clinical efficacy were observed between devices strengthens the observed differences in device satisfaction that favored Respimat $^{\circledR}$ SMI in this trial. ${ }^{27}$

\section{Comparisons with DPIs}

Patients' preferences for Respimat ${ }^{\circledR}$ SMI and the Turbuhaler ${ }^{\circledR}$ DPI were compared in a randomized, controlled study (Boehringer Ingelheim study number 1047.16) involving 153 patients (mean age 41 years) with moderate or severe asthma. ${ }^{48}$ Patients received the inhaled corticosteroid budesonide via one of the devices (randomly allocated) and placebo via the other in a double-dummy design for 12 weeks, and satisfaction was assessed by means of the PASAPQ at the end of the study. Total satisfaction scores for Respimat ${ }^{\circledR}$ SMI were significantly higher than for Turbuhaler ${ }^{\circledR}$ (difference 8.6, Table 4), as were those in the performance domain (difference 15.1, Figure 2a). For the population studied as a whole, this difference in the performance score exceeded the recommended MID. Although statistically significant, the observed total satisfaction score difference in favor of the Respimat ${ }^{\circledR}$ SMI (8.6) did not meet the MID criterion of 10 . However, 60 patients $(39.2 \%)$ did give a higher total satisfaction score for Respimat ${ }^{\circledR}$ SMI than for Turbuhaler ${ }^{\circledR}$ that met or exceeded the MID for the PASAPQ, whereas no patients gave a score for Turbuhaler ${ }^{\circledR}$ that exceeded the Respimat $^{\circledR}$ SMI score by this threshold. The proportion of patients who preferred Respimat ${ }^{\circledR}$ SMI was $73.7 \%$, with $17.1 \%$ preferring the Turbuhaler ${ }^{\circledR}$ and $9.2 \%$ expressing no preference for either device (Figure 1b). Patients' willingness to continue using the device was higher for Respimat ${ }^{\circledR}$ SMI than for Turbuhaler ${ }^{\circledR}$ (mean scores of 80 and 62, respectively, $P<0.0001){ }^{48}$

A second study that used the PASAPQ to compare satisfaction and preference with a DPI (Boehringer Ingelheim study number 215.1366) was conducted in 150 patients with COPD or asthma who added ipratropium bromide plus fenoterol in Respimat ${ }^{\circledR}$ SMI to their existing Diskus ${ }^{\circledR}$-based therapy (usually corticosteroid plus long-acting beta-agonist) for 4 weeks. ${ }^{49}$ At the end of the study, the mean total PASAPQ score was statistically, but not clinically significantly higher with Respimat ${ }^{\circledR}$ SMI than with Diskus ${ }^{\circledR}$ (Table 4), as were the mean scores for the two PASAPQ domains of performance and convenience (Figure 2b). Overall, 63.5\% of patients expressed a preference for Respimat ${ }^{\circledR}$ SMI, $33.8 \%$ for Diskus ${ }^{\circledR}$ and $2.7 \%$ expressed no preference for either device (Figure 1c).

\section{Conclusions}

Inhaled bronchodilator therapy has a central place in the management of COPD, but the choice of the most appropriate 
A)

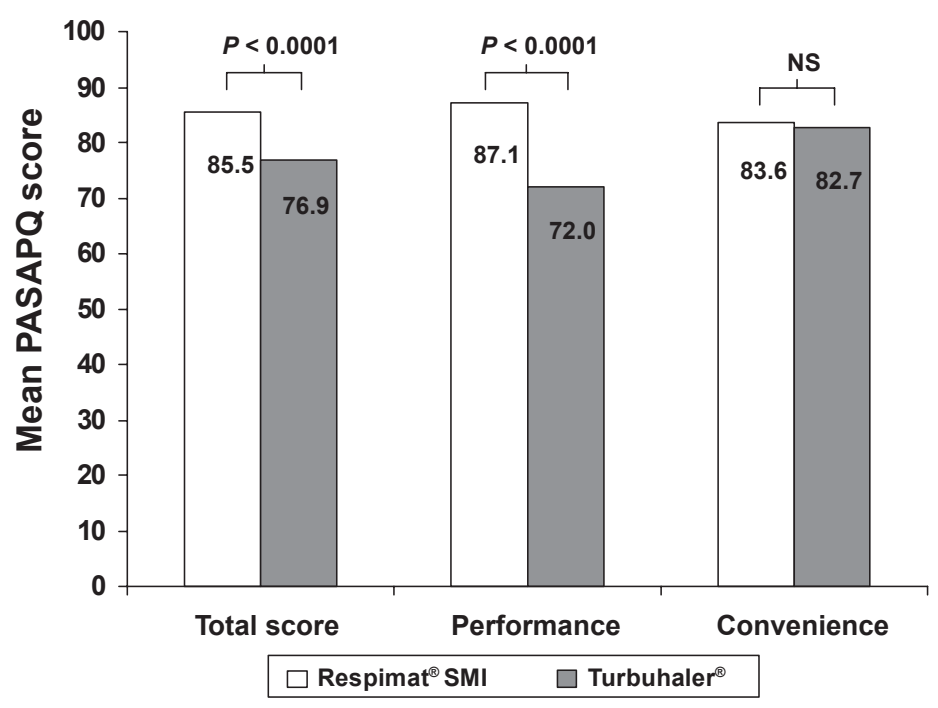

B)

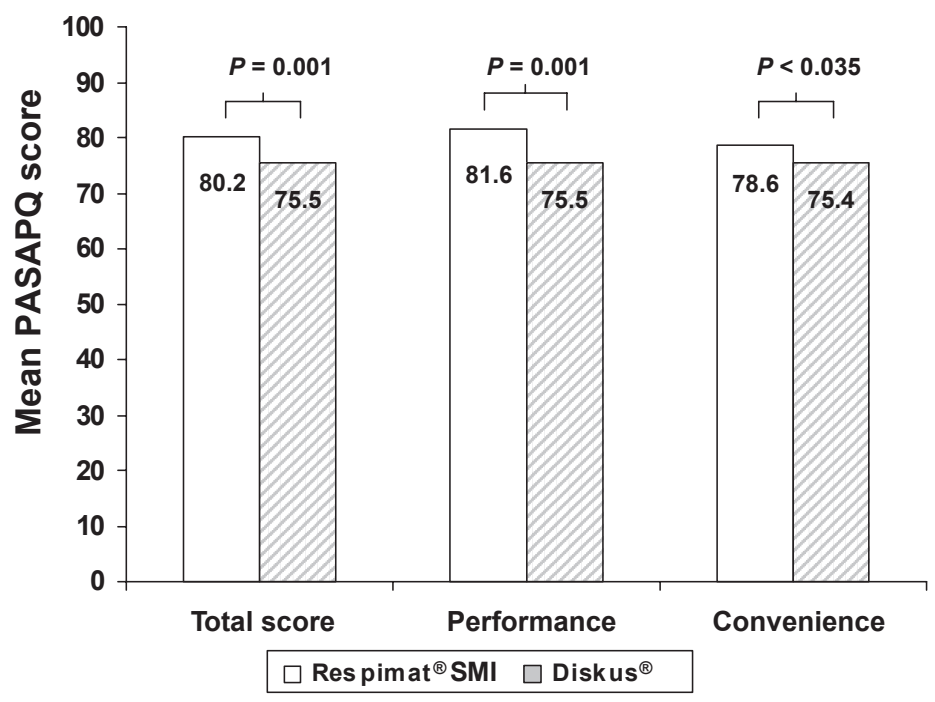

Figure 2 Mean PASAPQ satisfaction scores for Respimat ${ }^{\circledR}$ SMI compared with A) Turbuhaler ${ }^{\circledR}$ in a clinical study ${ }^{48}$ and B) Diskus ${ }^{\circledR}$ in an observational study. ${ }^{49}$ Total scores and performance and convenience domain scores are transformed to a scale of 0 to 100 points; $P$ values for differences between devices are from general linear models analysis $\left(\right.$ Turbuhaler $^{\circledR}$ ) and paired t-test (Diskus ${ }^{\circledR}$ ).

inhaler for a given patient is often not straightforward. The ease of use and performance characteristics of the inhaler will markedly influence patients' acceptance of the device, as will the patients' attitudes to their illness and chronic medication use in general. Clinicians, and patients with lung disease must choose the most appropriate inhaler for their needs from a vast and growing array of efficient devices. Implicit in selecting an inhaler is the as yet unproven (although widely accepted) assumption that patient preference for a device will promote better adherence with therapy, which will in turn lead to improved disease outcome. Although it has been difficult to demonstrate that this time-honoured preference-adherence-outcome paradigm is true, it does appear that in real life conditions, choice of inhaler device can have an impact on disease control, and that the patient/device interface is crucial for both asthma ${ }^{12,23,50,51}$ and COPD, where it has been shown that device adherence affects outcomes such as the frequency of exacerbations and hospitalizations. ${ }^{31,35}$

Studies with the Respimat ${ }^{\circledR}$ SMI have consistently shown that this device is well accepted by patients, and that patient total satisfaction with this device is higher than for the pMDI. Patient perception of the performance of the Respimat ${ }^{\mathbb{B}}$ SMI is also higher compared to the Turbuhaler ${ }^{\circledR}$ DPI. Importantly, many of these studies have used a robust and validated instrument 
(the PASAPQ) to measure patient satisfaction/preference. It is notable that the findings in patients participating in randomized clinical trials, whose ability to use inhalers is usually better than in day-to-day practice, have been confirmed by the findings of observational studies of Respimat ${ }^{\circledR}$ SMI in a primary care setting. The findings also seem to apply equally well to patients with COPD and asthma, despite differences between these patient groups in attitudes to disease and medication that might influence the basis for satisfaction and preference. ${ }^{15}$

A possible drawback when interpreting satisfaction and preference findings from studies that use active treatment arms is whether the medication inhaled from the device biases the patient's opinion of the device. The use of the PASAPQ helps to reduce bias because the questions in it were designed to be specific to attributes of the inhaler and, as it is self-administered, assessor bias is avoided. Bias can also be minimized by using a double-dummy design to help obviate the fact that patients cannot be blinded to inhalers that look and function differently. Such an approach was followed in two of the comparative trials described above. Bias may also be reduced by comparing the effect of a single drug treatment via two different inhalers, as was done in the Respimat ${ }^{\circledR}$ SMI vs Turbuhaler ${ }^{\circledR}$ comparison and the Respimat ${ }^{\circledR}$ vs pMDI crossover study. ${ }^{27,48}$ In the Respimat ${ }^{\circledR}$ SMI vsDiskus ${ }^{\circledR}$ comparison, ${ }^{49}$ patients were comparing an anticholinergic plus short-acting beta-agonist via Respimat ${ }^{\mathrm{R}}$ SMI with, in most cases, a corticosteroid plus long-acting beta-agonist combination via Diskus ${ }^{\circledR}$, so differences in bronchodilator efficacy, speed of onset and tolerability might have affected patients' satisfaction ratings.

The observed high patient preferences for Respimat ${ }^{\circledR}$ SMI over other devices might be expected to result in improved adherence to therapy and perhaps outcome, but this still needs to be tested prospectively, ideally in "real-life" settings using randomized controlled trials with broad inclusion criteria. Persistence with therapy is particularly important in COPD, because sustained adherence to bronchodilator therapy has been shown to slow the progressive decline in lung function ${ }^{5-8,52}$ and may possibly reduce mortality from this disabling disease. ${ }^{6,7}$ An inhaler such as the Respimat ${ }^{\circledR}$ SMI that is convenient to use, reliable, and well accepted by patients should offer advantages in this respect during long-term treatment. Such a device might be particularly appropriate in patients who are new to inhaled therapy, as it could offer the opportunity to establish a pattern of long-term adherence.

\section{Acknowledgments and Disclosures}

The authors would like to acknowledge the help of Roger Nutter (Lexeme) and David Macari (PAREXEL MMS Ltd) for their assistance in drafting this paper, which was funded jointly by Boehringer Ingelheim and Pfizer.

Respimat $^{\circledR}$ and Soft Mist ${ }^{\mathrm{TM}}$ are trade marks of the Boehringer Ingelheim group of companies. Turbuhaler ${ }^{\circledR}$ is a trade mark of the AstraZeneca group of companies. Diskus ${ }^{\circledR}$ is a trade mark of GlaxoSmithKline group of companies.

Drs Hodder and Price have received speakers' honoraria, consulting fees and research grants from various pharmaceutical companies including Boehringer Ingelheim and Pfizer.

\section{References}

1. MacNee W. Pathogenesis of Chronic Obstructive Pulmonary Disease. Proc Am Thorac Soc. 2005;2(4):258-266.

2. Calverley PM. Inhaled corticosteroids are beneficial in chronic obstructive pulmonary disease. Am J Respir Crit Care Med. 2000;161:341-342.

3. Global Initiative for Chronic Obstructive Lung Disease (GOLD). Global Strategy for the diagnosis, management and prevention of chronic obstructive pulmonary disease. Bethesda, National Institute of Health, National Heart, Lung, and Blood Institute 2003; NHLBI/WHO Workshop Report.

4. Sin DD, McAlister FA, Man SF, et al. Contemporary management of chronic obstructive pulmonary disease: scientific review. JAMA. 2003;290:2301-2312.

5. Celli BR, Thomas NE, Anderson JA, et al. Effect of Pharmacotherapy on Rate of Decline of Lung Function in Chronic Obstructive Pulmonary Disease: Results from the TORCH Study. Am J Respir Crit Care Med. 2008;178(4):332-338.

6. Suissa S, Ernst P, Vandemheen KL, Aaron SD. Methodological issues in therapeutic trials of COPD. Eur Respir J. 2008;31:927-933.

7. Tashkin DP, Celli B, Senn S, et al. for the UPLIFT Study Investigators. A 4 year trial of tiotropium in chronic obstructive pulmonary disease. N Engl J Med. 2008;359:1543-1554.

8. Decramer M, Celli B, Kesten S, Lystig T, Mehra S, Tashkin D. For the UPLIFT investigators. Effect of tiotropium on outcomes in patients with moderate chronic obstructive pulmonary disease (UPLIFT): a prespecified subgroup analysis of a randomized controlled trial. Lancet. Published online August 28, 2009;DOI:10.1016/S0140-6736(09)61298-8.

9. Newman SP. Inhaler treatment options in COPD. Eur Resp Rev. 2005; $14: 102-108$.

10. Crompton GK. Problems patients have using pressurized aerosol inhalers. Eur J Respir Dis Suppl. 1982;119:101-104.

11. Lindgren S, Bake B, Larsson S. Clinical consequences of inadequate inhalation technique in asthma therapy. Eur J Respir Dis. 1987; 70:93-98.

12. Giraud V, Roche N. Misuse of corticosteroid metered-dose inhaler is associated with decreased asthma stability. Eur Respir J. 2002;19: 246-251.

13. Pedersen S, Frost L, Arnfred T. Errors in inhalation technique and efficiency in inhaler use in asthmatic children. Allergy. 1986;41:118-124.

14. Bateman ED. Improving inhaler use in COPD and the role of patient preference. Eur Respir Rev. 2005;14:85-88.

15. Osman LM, Hyland ME. Patient needs and medication styles in COPD. Eur Respir Rev. 2005;14(96):89-92.

16. Anderson PJ. Patient preferences for and satisfaction with inhaler devices. Eur Respir Rev. 2005;14(96):109-116.

17. Hodder R. Design and interpretation of device preference trials: marketing tools or scientific instruments? Respiratory Drug Delivery. 2006;X:19-36.

18. Jones R, Hyland ME, Hanney K, et al. A qualitative study of compliance with medication and lifestyle modification in chronic obstructive pulmonary disease (COPD). Prim Care Respir J. 2004;13:149-154.

19. Rand CS. Patient adherence with COPD therapy. Eur Respir Rev. 2005;14(96):97-101. 
20. Osterberg L, Blaschke T. Adherence to medication. $N$ Engl J Med. 2005;353:487-497.

21. Brocklebank D, Ram F, Wright J, et al. Comparison of the effectiveness of inhaler devices in asthma and chronic obstructive airways disease: a systematic review of the literature. Health Technol Assess. 2001; 5:1-149.

22. Dolovich M, Ahrens RC, Hess D, et al. Device selection and outcomes of aerosol therapy: Evidence-based guidelines. Chest. 2005; 127:335-371.

23. Price D, Thomas M, Mitchell G, et al. Improvement of asthma control with a breath-actuated pressurised metered dose inhaler (BAI): a prescribing claims study of 5556 patients using a traditional pressurised metered dose inhaler (MDI) or a breath-actuated device. Respir Med. 2003;97:12-19.

24. Thomas M, Price D, Chrystyn H, et al. Inhaled corticosteroids for asthma: impact of practice level device switching on asthma control. BMC Pulm Med. 2009;9:1. URL: http://www.biomedcentral.com/ $1471-2466 / 9 / 1$.

25. Tjwa MKT. Budesonide inhaled via Turbuhaler: a more effective treatment for asthma than beclomethasone dipropionate via Rotahaler. Ann Allergy Asthma Immunol. 1995;75:107-111.

26. Fletcher M, Hardy AJ, Karbal B, et al. Effects of asthma training on inhaler device selection and utilization in general practice. Eur Respir J. 2004;24(Suppl 48):257s.

27. Schürmann W, Schmidtmann S, Moroni P, et al. Respimat ${ }^{\circledR}$ Soft Mist $^{\mathrm{TM}}$ inhaler versus hydrofluoroalkane metered dose inhaler: Patient preference and satisfaction. Treat Respir Med. 2005;4:53-61.

28. Lenney J, Innes JA, Crompton GK. Inappropriate inhaler use: assessment of use and patient preference of seven inhalation devices. Respir Med. 2000;84:496-500.

29. Bourbeau J, Bartlett SJ. Patient adherence in COPD. Thorax. 2008;63:831-838.

30. Rand CS, Nides M, Cowles M, et al. Long-term metered dose inhaler adherence in a clinical trial. The Lung Health Study Research Group. Am J Respir Crit Care Med. 1995;152:580-588.

31. Balkrishnan R, Christensen D. Inhaled corticosteroid use and associated outcomes in elderly patients with moderate to severe chronic pulmonary disease. Clin Ther. 2000;22:452-469.

32. Canonica $\mathrm{G}$, Baena-Cagnani $\mathrm{C}$, Blaiss $\mathrm{M}$, et al. Unmet needs in asthma. Global Asthma Physician and Patient (GAPP) survey: global adult findings. Allergy. 2007;62:668-674.

33. Adams R, Fuhlbrigge A, Guilbert T, et al. Inadequate use of asthma medication in the United states: results of the Asthma in America national population survey. J Allergy Clin Immunol. 2002;110: $58-64$.

34. Rabe K, Adachi M, Lai C, et al. Worldwide severity and control of asthma in children and adults: the global asthma insights and reality surveys. J Allergy Clin Immunol. 2004;114:40-47.

35. Corden Z, Bosley C, Rees P, et al. Home nebulized therapy for patients with COPD: patient compliance with treatment and its relation to quality of life. Chest. 1997;112:1278-1282.

36. Hochrainer D, Hölz H, Kreher C, et al. Comparison of the aerosol velocity and spray duration of Respimat ${ }^{\circledR}$ Soft Mist ${ }^{\mathrm{TM}}$ inhaler and pressurized metered dose inhalers. J Aerosol Med. 2005;18: $273-282$.
37. Newman SP. Use of gamma scintigraphy to evaluate the performance of new inhalers. J Aerosol Med. 1999;12 Suppl 1:S25-S31.

38. Pitcairn G, Reader SJ, Pavia D, et al. Deposition of corticosteroid aerosol in the human lung by Respimat ${ }^{\mathbb{R}}$ Soft Mist ${ }^{\mathrm{TM}}$ inhaler compared to deposition by metered dose inhaler or by Turbuhaler ${ }^{\mathbb{B}}$ dry powder inhaler. J Aerosol Med. 2005;18:S264-S272.

39. Kässner F, Hodder R, Bateman ED. A review of ipratropium bromide/ fenoterol hydrobromide $\left(\right.$ Berodual $^{\circledR}$ ) delivered via Respimat ${ }^{\circledR}$ Soft Mist ${ }^{\mathrm{TM}}$ Inhaler in patients with asthma and chronic obstructive pulmonary disease. Drugs. 2004;64:1671-1682.

40. Brand P, Hederer B, Austen G, et al. Higher lung deposition with Respimat Soft Mist Inhaler than HFA-MDI in COPD patients with poor technique. Int J Chron Obstruct Pulmon Dis. 2008;3: 763-770.

41. Atkinson MJ, Sinha A, Hass SL, et al. Validation of a general measure of treatment satisfaction, the Treatment Satisfaction Questionnaire for Medication (TSQM), using a national panel study of chronic disease. Health Qual Life Outcomes. 2004;2:12.

42. Shikiar R, Rentz AM. Satisfaction with medication: an overview of conceptual, methodologic, and regulatory issues. Value Health. 2004; 7:204-215.

43. Welch MJ. Comparison of patient preference and ease of teaching inhaler technique for pulmicort Turbuhaler ${ }^{\circledR}$ versus pressurized metereddose inhalers. J Aerosol Med. 2004;17:129-139.

44. Kozma CM, Slaton TL, Monz BU, et al. Development and validation of a patient satisfaction and preference questionnaire for inhalation devices. Treat Respir Med. 2005;4:41-52.

45. Monz B, Kozma C, Reese P, Slaton T, Hodder R. Patient Satisfaction and Preference Questionnaire (PASAPQ) User Manual. Copyright, Boehringer Ingelheim International GmbH, 2005. Brigitta.Monz@ing. Boehringer-ingelheim.com.

46. Kardos P, Golisch W, Wolf K. New soft mist inhaler is effective and easy to use in patients with asthma and COPD [abstract]. Eur Respir J. 2005;26(Suppl 49):338s.

47. Freytag F, Golisch W, Wolf K. COPD and asthma patients are satisfied with handling and inhalation characteristics of Soft Mist ${ }^{\mathrm{TM}}$ (Berodual ${ }^{\circledR}$ Respimat $^{\mathbb{R}}$ ). Eur Respir J. 2006;28 (Suppl 50):739s.

48. Hodder R, Reese PR, Slaton T. Asthma patients prefer Respimat ${ }^{\circledR}$ Soft Mist $^{\mathrm{TM}}$ Inhaler to Turbuhaler ${ }^{\circledR}$. Int J COPD. 2009;4:225-232.

49. Freytag F, Rau-Berger H, Glaab T, et al. Respimat ${ }^{\circledR}$ Soft Mist ${ }^{\mathrm{TM}}$ Inhaler preferred to Diskus by patients with COPD and/or asthma. Am J Respir Crit Care Med. 2007;175:A639.

50. Stoloff SW, Stempel DA, Meyer J, et al. Improved refill persistence with fluticasone propionate and salmeterol in a single inhaler compared with other controller therapies. J Allergy Clin Immunol. 2004;113: $245-251$.

51. O'Connor RD, Rosenzweig JR, Stanford RH, et al. Asthma-related exacerbations, therapy switching, and therapy discontinuation: a comparison of 3 commonly used controller regimens. Ann Allergy Asthma Immunol. 2005;95:535-540.

52. Suissa S. Medications to modify lung function decline in chronic obstructive pulmonary disease: some hopeful signs. Am J Respir Crit Care Med. 2008;178(4):322-323.
International Journal of COPD

\section{Publish your work in this journal}

The International Journal of COPD is an international, peer-reviewed journal of therapeutics and pharmacology focusing on concise rapid reporting of clinical studies and reviews in COPD. Special focus is given to the pathophysiological processes underlying the disease, intervention programs, patient focused education, and self management protocols.

\section{Dovepress}

This journal is indexed on PubMed Central, MedLine and CAS. The manuscript management system is completely online and includes a very quick and fair peer-review system, which is all easy to use. Visit $\mathrm{http}: / /$ www.dovepress.com/testimonials.php to read real quotes from published authors. 